\title{
Comparison between Strain-Based vs. Stress-Based Criteria in Seismic Performance Evaluation of High Arch Dams
}

\author{
Masood Heshmati ${ }^{1,}$, , Seyed Mohammad Seyed Kolbadi ${ }^{2}$, Seyed Mahdi Seyed Kolbadi ${ }^{1}$ \\ ${ }^{1}$ Department of Civil Engineering, K. N. Toosi University of Technology, Tehran, Iran \\ ${ }^{2}$ Departmet of Civil Engineering, Lame'i Gorgani University, Tehran, Iran
}

\section{Email address:}

masood_heshmati@sina.kntu.ac.ir(M. Heshmati), mohamad.kolbadi.pwut@gmail.com (S. M. S. Kolbadi), mahdi_kolbadi@sina.kntu.ac.ir (S. M. S. Kolbadi)

\section{To cite this article:}

Masood Heshmati, Seyed Mohammad Seyed Kolbadi, Seyed Mahdi Seyed Kolbadi. Comparison between Strain-Based vs. Stress-Based Criteria in Seismic Performance Evaluation of High Arch Dams. American Journal of Civil Engineering. Special Issue: al Analysis Progresses: Designing, Analyzing and Testing. Vol. 3, No. 2-1, 2015, pp. 1-8. doi: 10.11648/j.ajce.s.2015030201.11

\begin{abstract}
In the present paper, seismic performance of a high concrete arch dam is evaluated based on both the stress and strain criteria. For this purpose, the finite element model of the selected arch dam-reservoir-foundation system was provided. Reservoir was modeled using Eulerian approach as a compressible domain and the foundation rock was assumed to be massless. Dynamic equilibrium equations for the coupled system were solved using Newmark's time integration algorithm. Seismic performance evaluation of dam-foundation-reservoir systems were performed considering parameters such as demand-capacity ratio, cumulative inelastic duration and extension of overstressed (or overstrained) areas obtained from linear elastic analyses and compared with the real crack profile from nonlinear analysis. It was found that although results obtained for the stress and strain rules have similarities, performance evaluation based on the strain gives different results which can be lead to different decision making in dam safety related projects.
\end{abstract}

Keywords: Arch Dam, Cumulative Inelastic Duration, Demand-Capacity Ratio, Seismic Performance Evaluation, Strain-Based Criteria

\section{Introduction}

Performance of arch dams maybe evaluated in linear or nonlinear phase considering various assumptions for material and loading. Generally, it's common to evaluate seismic behavior in linear phase considering various parameters and; in the case of extensive damage within the dam body, nonlinear analysis of the system should be conducted.

Several researchers such as Ghanaat [Ghanaat, Y. 2004, Ghanaat, Y. 2002]; Fok [Fok and Chopra, 1986]; Yamaguchi et al. [Yamaguchi, Y. et al. 2004], Bayraktar [Bayraktar, A., et al. 2009] and Hariri et al [Hariri Ardebili and Mirzabozorg and Ghaemian, 2011] have investigated seismic performance of concrete arch dams. Hall et al. [Hall and Matheu, and Liu, 1999] proposed some indices for systematic comparison of various ground motions effects. Ghanaat [Ghanaat, Y. 2002] proposed a methodology for damage estimation in concrete dams which can be found in USACE guideline [US Army
Corps of Engineers (USACE), 2007]. Bayraktar [Bayraktar, A., et al. 2009] evaluated seismic performance of concrete gravity, arch, roller-compact-concrete (RCC) and concreteface-rock fill-dam (CFRD) dams using indices proposed by USACE subjecting to near and far fault ground motions. Hariri et al. [Hariri Ardebili and Mirzabozorg and Ghaemian, 2011] investigated the effect of water level on dynamic performance of arch dams.

Wieland and Fan [Wieland and Fan, 2004], Wieland et al. [Wieland and Brennerand Sommer, 2003] investigated behavior of concrete dams under recent earthquake. Studer [Studer, 2004] was studied seismic performance of new and existing dams using methods proposed by international committee of large dams and expressed that the general procedure is clear and straightforward while practically detailed information are needed. Yamaguchi et al. 
[Yamaguchi, Y. et al. 2004] discussed the role of nonlinear dynamic analyses in seismic evaluation problems of 2D concrete gravity dams. They examined the application of linear analyses in term of demand-capacity ratio (DCR) to provide qualitative estimates of potential level of damage under moderately severe excitations. Also, Hariri and Mirzabozorg [Hariri Ardebili and Mirzabozorg, 2011] studied seismic performance of concrete arch dams using real ground motions and also Endurance Time Acceleration Functions (ETAFs).

All previous researches utilize the stress to determine seismic behavior of concrete dams. However, it's important to note that behavior of concrete is based on the strain. In the present paper the common criteria for seismic assessment of concrete arch dams based on the stress are substituted by similar criteria, which are based on the strain rule. A high concrete arch dam is modeled for this purpose and evaluated using stress-based and strain-based rules. The results are compared with each other using the parameters such as the DCR, cumulative inelastic duration (CID) and percentage of overstressed (or overstrained) areas within the dam body in various performance levels.

\section{Behavior of Mass Concrete}

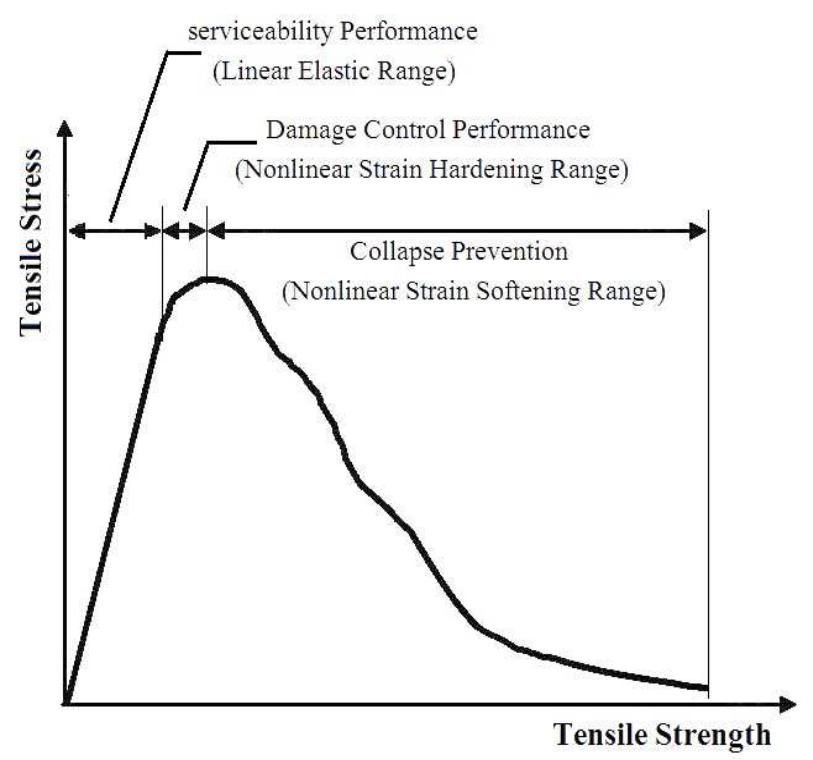

Figure 1. Conventional stress-strain relation for mass concrete structures (USACE, 2007)

Actual response of massive concrete structures to earthquake ground motions is very complicated. Loading histories and rapid seismic strain rates have important roles in structural performance (USACE, 2007). As it is known, mass concrete has limited ductile behavior. This behavior is characterized by a stress-strain relation composed of elastic and inelastic strain ranges followed by a complete loss of strength (USACE, 2007). Typical tensile stress-strain diagram of mass concrete is shown in Figure 1. The curve is divided into the three parts. In the first section, in which concrete behaves as a linear elastic (LE) material, the dam called to have serviceability performance. The second part is inelastic-strain hardening range which called as damage control phase and provides only limited inelastic behavior in the dam body. In this situation damage may be significant but all cracking and joint openings are limited and discrete [Ghanaat, Y. 2002]. Except for unlikely MCE events, it is desired to prevent damage in main elements such as foundation and other inaccessible structural elements. A LE analysis combined with a predefined performance evaluation criteria can be used to assess the dam response in the damage control phase. The dam response beyond the damage control range is governed by complete loss of strength, sliding, and nonlinear response behavior of discrete blocks bounded by opened joints and cracked sections and called as collapse prevention performance. This behavior must be evaluated using nonlinear time-history analysis [US Army Corps of Engineers (USACE), 2007].

\section{Methodology of Performance Evaluation}

Figure 2 describes the proposed flowchart for seismic evaluation of concrete arch dams using stress-based and strain-based methodology. Seismic performance of concrete arch dams is evaluated in accordance with displacements, stresses, strains, demand-capacity ratio, cumulative inelastic duration and spatial extension of overstressed (or overstrained) areas $\left(\mathrm{A}^{\text {overstress }}\right.$ or $\left.\mathrm{A}^{\text {overstrain }}\right)$ on the upstream (US) and downstream (DS) faces of the dam body.

\subsection{Demand-Capacity Ratio}

For arch dams where high stresses and strains are usually oriented in the arch and cantilever directions, DCR refers to the ratio of calculated arch or cantilever stress (or strain) to the tensile strength of mass concrete or its equivalent strain, but it can also be developed for principal stresses (or strains) [Ghanaat, Y. 2002]. Tensile strength of mass concrete used in computation of DCR is obtained from uni-axial splitting tension tests or from Raphael proposed diagram (Raphael, 1984).It should be noticed that the DCR used in this method is the ratio of dynamic stresses (or strains) to static tensile strength (or its corresponding strain) and should be used in conjunction with other criteria for safety evaluation of concrete dams. In the method proposed by USACE, the mass concrete is assumed as homogeneous isotropic material and so its properties in three principal directions are the same. Also the static tensile strain of the concrete is calculated at the end of the linear part of stress-strain curve showed in Figure 1 and in fact just considers the serviceability performance range. The strains in dynamic range are approximately time-independent and are calculated using dynamic modulus of elasticity and Poisson's ratio of concrete.

\subsection{Cumulative Inelastic Duration}

Cumulative inelastic duration, which is a measure of energy, accounts for magnitudes as well as duration of stress 
(or strain) excursions. It refers to the total duration of stress (or strain) excursions above a stress (or strain) level associated with a certain DCR (Ghanaat, 2004). As shown in the flowchart introduced in Figure 2, the behavior of the dam is evaluated in three zones based on the estimated damage severity. The Performance Threshold Curve (PTC) for arch dams is shown in Figure 3 (Ghanaat, 2004 and USACE, 2007).

\subsection{Spatial Extension of Overstressed (or Overstrained) Areas}

In addition to foregoing performance criteria, introduced damage criteria require to be bounded in the limited areas, so that evaluation based on LE analysis is still valid. If spatial extent of damage or nonlinear response is limited to $20 \%$ of the total areas on the upstream or downstream faces, LE analysis is valid (USACE, 2007).

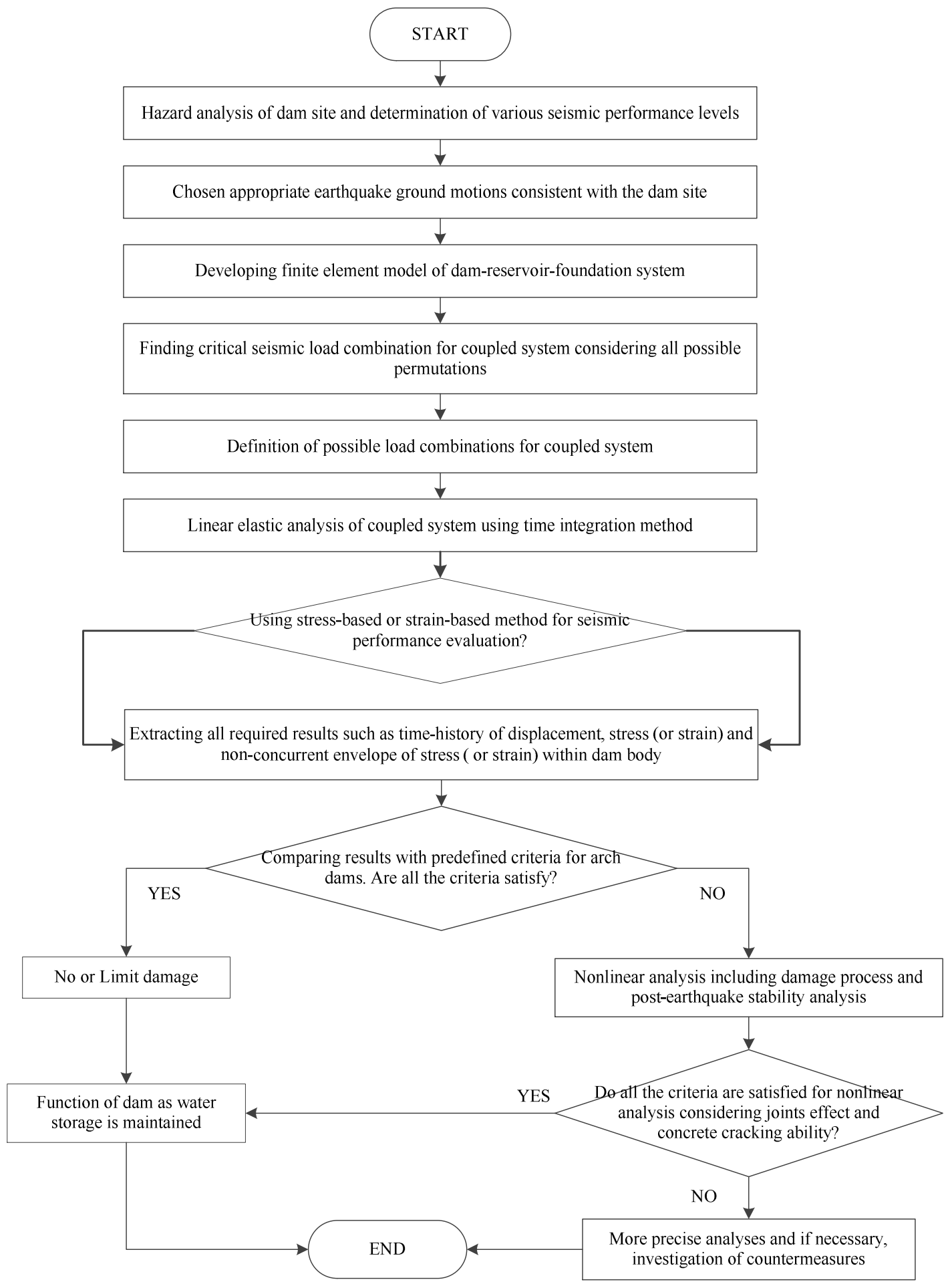

Figure 2. Flowchart for seismic performance evaluation of arch dams using stress- (or strain-) based 
Table 1. Quantifying the limit-states

\begin{tabular}{llllll|}
\hline Limit-States & DCR & & DCR-CID Diagram & & $\mathbf{A}^{\text {overstress }} / \mathbf{A}^{\text {overstrain }}$ \\
\hline Minor or No Damage & DCR $\leq 1.0$ & $\&$ & Zone I & $\&$ & $0.0 \%$ \\
Acceptable Level of Damage & $1.0<\mathrm{DCR}<2.0$ & $\&$ & Zone II & \& & $\leq 20.0 \%$ \\
Severe Damage & DCR $\geq 2.0$ & or & Zone III & or & $>20.0 \%$ \\
\hline
\end{tabular}

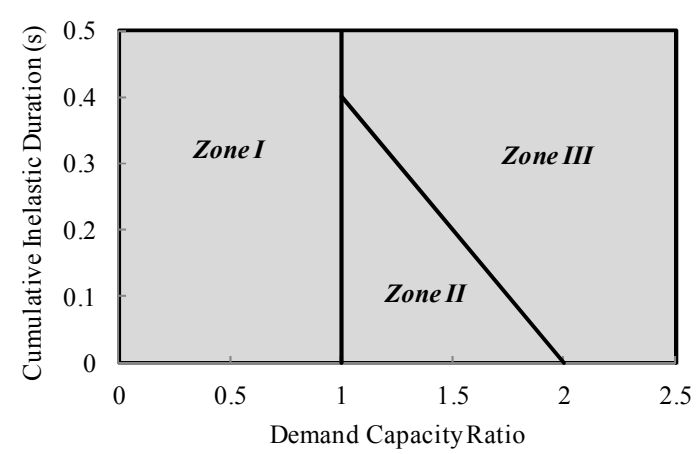

Figure 3. Zoning the CID-DCR diagram and Performance Threshold Curve (PTC) for arch dams

\subsection{Quantification of Limit-States}

Herein, the utilized methodology for quantifying the defined limit-states in the previous section is introduced. This method uses a combination of all previously defined criteria in conjunction with LE analysis for both stress-based and strain-based rules. Table 1 represents the tabular form of the introduced criteria for performance evaluation of arch dams.

\section{Case Description}

\subsection{Finite Element Model of DEZ Dam}

Dez high double curvature arch dam is selected as the numerical example. Total height of the dam is $203 \mathrm{~m}$ but the height above its concrete plug (the simulated dam) is $194 \mathrm{~m}$. Also, the height of the main body sitting on the concrete saddle is $186 \mathrm{~m}$. Thickness of the dam at the crest is $4.5 \mathrm{~m}$ and its maximum thickness at the base is $21 \mathrm{~m}$. Rectangular shaped mass-less foundation is used in this case while reservoir length modeled is about five times of the dam height. The provided finite element model is shown in Figure 4, which consists of 792 eight-node solid elements in the body and 3770 elements in the surrounding foundation rock. In this model, hexagonal elements are used in the dam body, while prism elements are utilized at some localized regions with irregular geometry. Also, 3660 eight-node Eulerain fluid elements are used to model the reservoir domain.

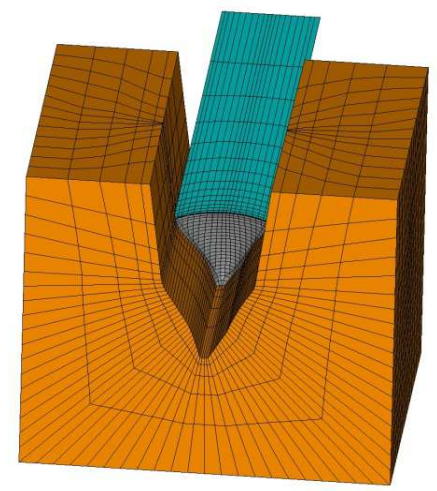

Figure 4. Finite element model of dam-reservoir-foundation system;Dez Dam

\subsection{Material Properties}

Material properties for mass concrete and foundation rock are given in Table 2 [Hariri Ardebili et al., 2011].The reservoir water density is taken as $1000 \mathrm{~kg} / \mathrm{m}^{3}$, the sound velocity is $1440 \mathrm{~m} / \mathrm{s}$ in water and the wave reflection coefficient for the reservoir around boundaries is taken 0.8 , conservatively.

Table 2. Material properties for the dam body and its surrounding foundation

\begin{tabular}{llll}
\hline & Properties & Static Values & Dynamic Values \\
\hline & Modulus of Elasticity & $40 \mathrm{GPa}$ & $46 \mathrm{GPa}$ \\
& Poisson's Ratio & 0.2 & 0.14 \\
Mass concrete & Mass Density & $2400 \mathrm{~kg} / \mathrm{m}^{3}$ & $36.5 \mathrm{MPa}$ \\
& Compressive Strength & $35 \mathrm{MPa}$ & $5.1 \mathrm{MPa}$ \\
& Tensile strength & $3.4 \mathrm{MPa}$ & \\
& Thermal expansion coefficient & $6 \times 10^{-6} /{ }^{\circ} \mathrm{C}$ & $13 \mathrm{GPa}$ \\
Foundation rock & Deformation Modulus-Saturated & $15 \mathrm{GPa}$ & \\
& Deformation Modulus-Unsaturated & 0.25 & \\
\hline
\end{tabular}

\section{Loading the Coupled System}

The applied loads are the dam body self-weight, hydrostatic pressure in summer condition, thermal loads and finally seismic loads based on seismic hazard analysis of the dam site.
The applied load combinations are presented in Table.3. In this table, each load combination is shown with an abbreviation in which the first letter represents the dam name, the second one represents the thermal load conditions ( $\mathrm{S}$ indicates summer), the three other letters are the level of the seismic excitation and 
the final two numbers represents No. of earthquake ground

dam in each excitation levels (Table 4).

motions. Nine ground motions are used for analysis of Dez

Table 3. Applied load combinations

\begin{tabular}{lll}
\hline Dam name & Abbreviation & Definition \\
\hline DEZ Dam & D-S-MDE09 & W $+\mathrm{h}_{\mathrm{s}}(\mathrm{NWL})+\mathrm{T}_{\mathrm{s}}+\mathrm{MDE}^{1}$ \\
\hline
\end{tabular}

W: Dam Self-Weight

$h_{s}$ : Hydrostatic Pressure

NWL: Normal Water Level

$\mathrm{T}_{\mathrm{s}}$ : Summer Temperature

${ }^{1}$ Maximum Design Earthquake

Table 4. Characteristics of ground motions

\begin{tabular}{llll}
\hline Excitation Level & NO & Earthquake Name & Station \\
\hline & 1 & DUZCE & At 1061 Lamond station \\
& 2 & LOMA-PRIETA & At 47006 Gilroy-GalivanColl station \\
& 3 & MANJIL & At Abbar station \\
MDE & NORTH RIDGE 1 & At 24088 Pacoima Kagel Canyon station \\
& 5 & NORTH RIDGE 2 & At 90059 Burbank Howard Rd station \\
& 6 & QAEN & At Qaen station \\
& 7 & SAN FERNANDO & At 128 Lake Hughes \# 12 station \\
& 8 & SPITAK & At Gukasyan station \\
\hline
\end{tabular}

All ground motions are scaled based on the horizontal and vertical components of the design response spectrums' considering 5\% for damping as shown in Figure 5 (USACE, 2007; Zhang et al., 2009; Chen et al., 2012) .The $\beta$-Newmark time integration method is utilized to solve the coupled problem of dam-reservoir-foundation model and finally, the system is excited at the foundation boundaries using the scaled earthquake records. Moreover, structural damping is taken to be $5 \%$ of critical damping in the conducted analyses. The thermal distribution within the dam body is obtained from the thermal transient analysis of the dam considering water temperature, air temperature and solar radiation recorded at the site. The temperatures obtained on the upstream and downstream faces of the dam body along the crown cantilever for the winter and summer conditions are shown in Figure 6.

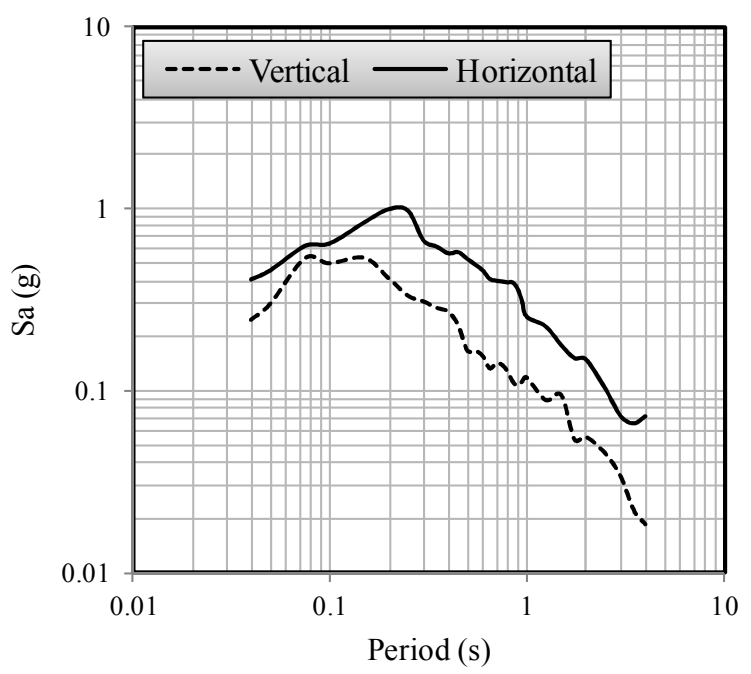

Figure 5. Design response spectrum $M D L$

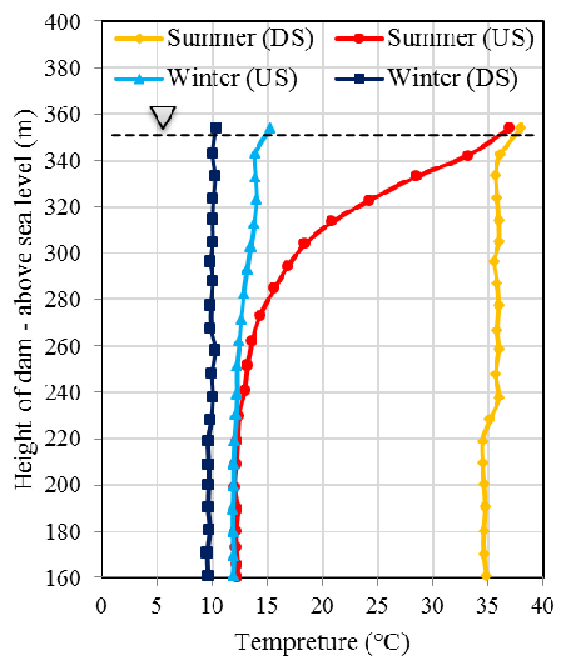

Figure 6. Temperatures distribution on the upstream and downstream faces of the dam body along the crown cantilever

\section{Results and Discussion}

\subsection{Performance in $M D E$}

All records are scaled to maximum design level. Figure 7 represents performance curves for the most critical node within the dam body. In both the stress-based and strainbased approaches, the dam expected to experience nonlinear behavior (some observed DCRs are greater than 2). Generally, the calculated inelastic durations using the stress-based method are higher than those in the strain-based method. The averages of cumulative inelastic durations at $\mathrm{DCR}=1.0$ and $\mathrm{DCR}=2.0$ for the stress- based method are $0.70 \mathrm{~s}, 0.11 \mathrm{~s}$ and these values for the strain-based method are $0.58 \mathrm{~s}$ and $0.07 \mathrm{~s}$, respectively. So, using the strain-based approach decreases the cumulative inelastic duration about $17.1 \%$ for $\mathrm{DCR}=1.0$ 
and $36.4 \%$ for $\mathrm{DCR}=2.0$ in $\mathrm{MDE}$.

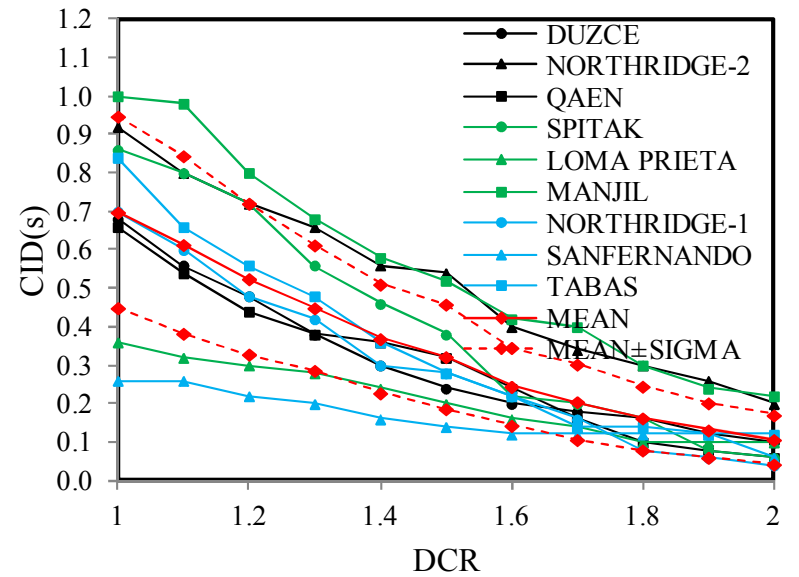

(a)

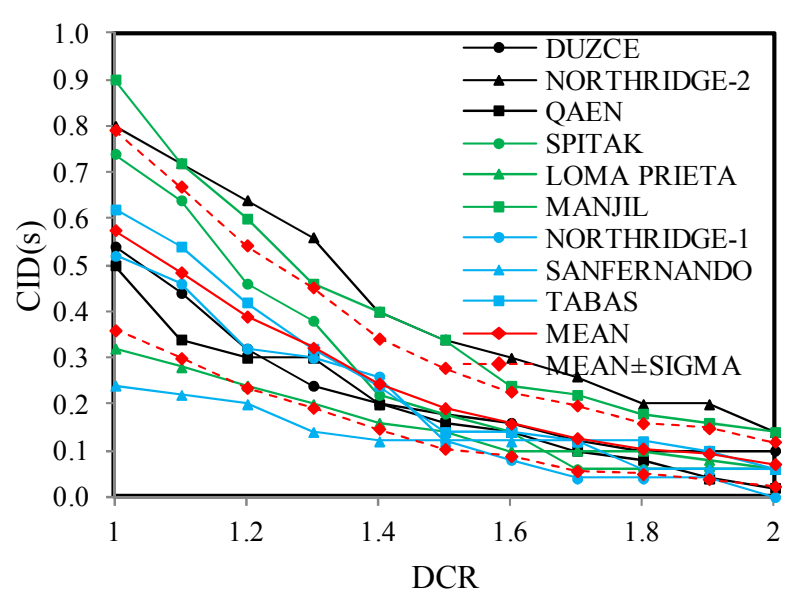

(b)

Figure 7. Performance curves in term of CID-DCR for critical nodes in the dam in MDE; (a) stress-based approach; (b) strain-based approach

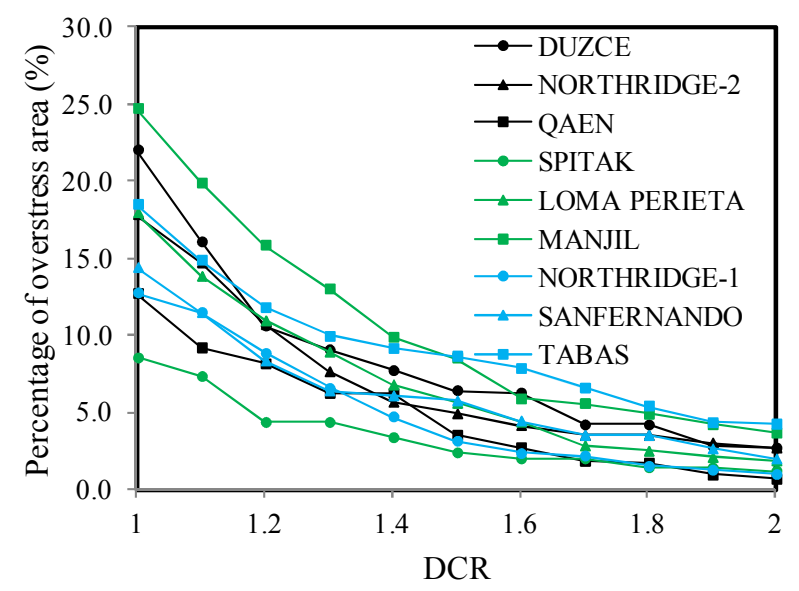

(a)

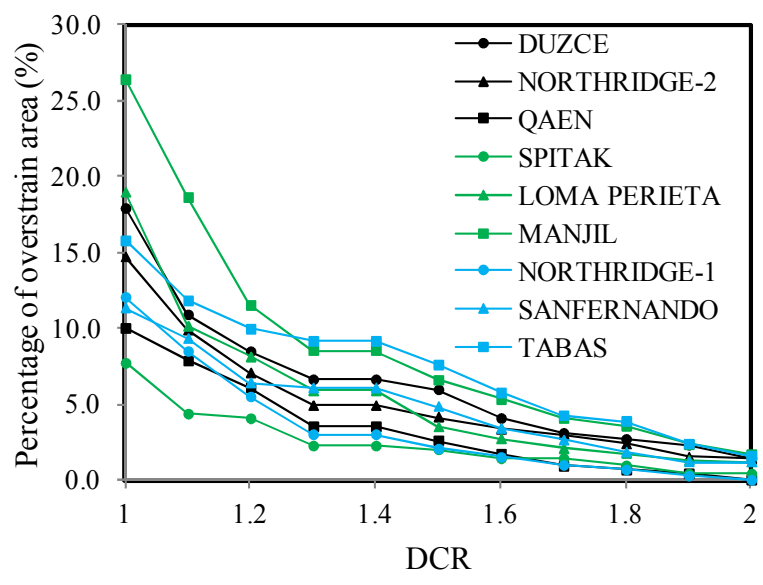

(b)

Figure 8. Percentage of (a) overstressed; (b) overstrained areas on the upstream face of the dam body in MDE

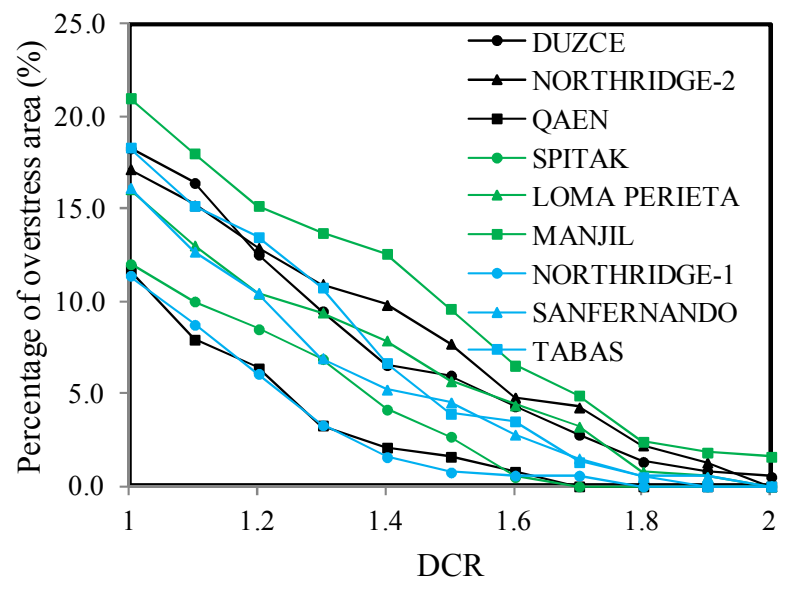

(a)

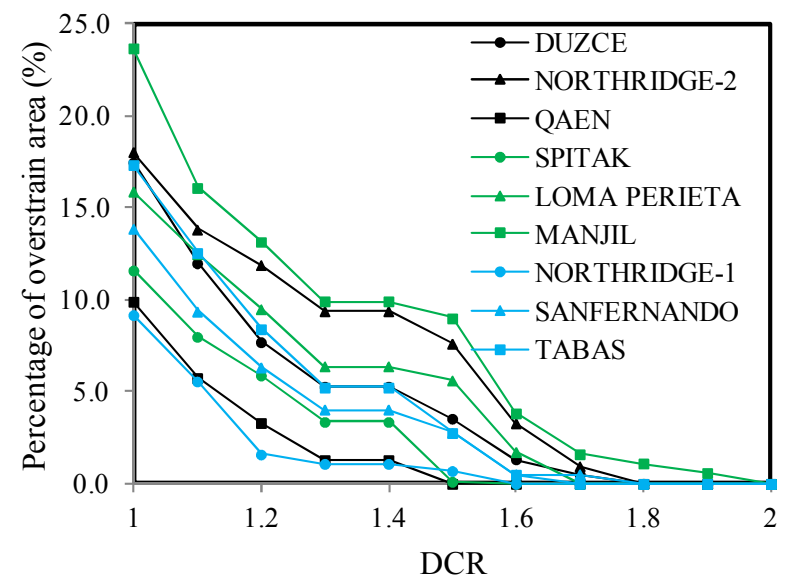

(b)

Figure 9. Percentage of (a) overstressed; (b) overstrained areas on the downstream face of the dam body in MDE

Figures 8 and 9 represent the percentages of overstressed and overstrained areas on both the upstream and downstream faces of the dam body. analysis of the system in MDE shows that using the strain-based method increases the percentage 
of critical areas on both the upstream and downstream faces for some of ground motions in lower DCRs, while decreases percentage of critical areas in higher DCRs.

\subsection{Discussion on the Results}

Comparing stress- (or strain-) based approaches show that using the strain-based method leads to lower extension of critical areas in the higher DCRs. On the downstream face there is no overstrained areasin $\mathrm{DCR}=2.0$ while at least three ground motions generate overstressed areas with $\mathrm{DCR}=2.0$. Based on Table 1, all of ground motions lead to the results exceeding the predefined threshold curve for overstressed areas, while only six of them lead to the results above the predefined overstrained areas on the upstream face. So, the dam body experiences severe damage in the forms of joint opening and concrete cracking for all ground motions when the stress-based approach is used for results interpretation, while using strain-based approach reduces the probability of severe damage.

\section{Conclusion}

As pointed, all the guides and criteria for structural performance assessment of concrete arch dams in the literature are based on the stress. However, the behavior of mass concrete is governed by the strain. In the present paper, the seismic performance assessment of concrete arch dams was considered using the criteria based on both the stress and the strain. For this purpose Dez dam, which is a high double curvature arch dam, was selected and the numerical model of the dam-reservoir-foundation was provided using the finite element technique. Nine earthquake records were selected and all of them were scaled using the site response spectra in MDE. Linear analyses of the system in this level were conducted

Based on the conducted linear analyses, it was found that in spite of some similarities between the results obtained for the stress and strain based approaches. Interpreting the results based on the stress-based criteria can lead to different decision making in the dams' safety related projects.

\section{Abbreviations}

$\begin{array}{ll}\text { USACE } & \text { US Army Corps of Engineers } \\ \text { RCC } & \text { Roller Compact Concrete } \\ \text { CFRD } & \text { Concrete Face Rock-fill Dam } \\ \text { ETAF } & \text { Endurance Time Acceleration Functions } \\ \text { DCR } & \text { Demand Capacity Ratio } \\ \text { CID } & \text { Cumulative Inelastic Duration } \\ \text { LE } & \text { Linear Elastic } \\ \text { US } & \text { Upstream } \\ \text { DS } & \text { Downstream } \\ \text { PTC } & \text { Performance Threshold Curve } \\ \text { DBE } & \text { Design Base Earthquake } \\ \text { MDE } & \text { Maximum Design Earthquake } \\ \text { MCE } & \text { Maximum Credible Earthquake }\end{array}$

\section{References}

[1] Bayraktar, A., et al. (2009), "Comparison of near and far fault ground motion effects on the seismic performance evaluation of dam-reservoir-foundation systems", Dam Engineering, XIX (4), 201-239.

[2] Chen, D.H., Du, C.B., Yuan, J.W. and Hong, Y.W., (2012), "An Investigation into the Influence of Damping on the Earthquake Response Analysis of a High Arch Dam", Journal of Earthquake Engineering, 16(3), pp.329-349.

[3] Fok, K.L. and Chopra, A.K. (1986), "Hydrodynamic and foundation flexibility effects in earthquake response of arch dams", Journal of Structural Engineering, 112 (8), 1810-1828.

[4] Ghanaat, Y., (2004), "Failure modes approach to safety evaluation of dams", 13th World Conference on earthquake engineering, Vancouver, B.C., Canada.

[5] Ghanaat, Y., (2002), "Seismic performance and damage criteria for concrete dams", Proceedings of the 3rd US-Japan Workshop on Advanced Research on Earthquake Engineering for Dams. San Diego, California.

[6] Hall, R. L., Matheu, E. E., and Liu, T. C., (1999), "Performance evaluation of the seismic response of concrete gravity dams", International Conference on Health Monitoring of Civil Infrastructure Systems, Chongqing, China.

[7] Hariri-Ardebili, M.A. and Mirzabozorg, H., (2011), "Investigation of Endurance Time Method Capability in Seismic Performance Evaluation of Concrete Arch Dams", Journal of Dam Engineering, XXII (1), 35-64.

[8] Hariri-Ardebili, M.A., Mirzabozorg, H., Ghaemian, M., Akhavan, M. and Amini, R., (2011), "Calibration of 3D FE model of DEZ high arch dam in thermal and static conditions using instruments and site observation", Proceeding of the 6th International Conference in Dam Engineering, Lisbon, Portugal.

[9] Hariri-Ardebili, M.A., Mirzabozorg, H. andGhaemian, M., (2011),"Seismic performance evaluation of high arch dams considering reservoir fluctuation", Proceeding of the 6th International Conference in Dam Engineering, Lisbon, Portugal.

[10] Hariri-Ardebili, M.A., Kolbadi, S.M., Heshmati, M. and Mirzabozorg, M., (2012), "Nonlinear Analysis of Concrete Structural Components using Co-axial Rotating Smeared Crack Model", Journal of Applied Science, 12(3), pp.221-232.

[11] Raphael, J. M. (1984), "The Tensile Strength of Concrete", ACI Journal Proceedings, 81, pp. 158-165.

[12] Studer, J.A., (2004), "Evaluation of earthquake safety of new and existing dams: Trends and experience", 13th World Conference on Earthquake Engineering, Vancouver, B.C., Canada, August, Paper No. 233.

[13] US Army Corps of Engineers (USACE), (2007)."EM 1110-26053: Earthquake design and evaluation of concrete hydraulic structures", Washington, D.C.

[14] Yamaguchi, Y., Hall, R., Sasaki, T., Matheu, E., Kanenawa, K., Chudgar, A., and Yule, D., (2004), "Seismic performance evaluation of concrete gravity dams", Proceedings of the 13th World Conference on Earthquake Engineering, Vancouver, B.C., Canada, August, Paper No. 1068. 
[15] Wieland, M., and Fan, B.H., (2004), "The activities of the international commission on large dams (ICOLD) in the earthquake safety of large dams", Proceedings of the 13th World Conference on Earthquake Engineering, Vancouver, B.C., Canada, August, Paper No. 5051.

[16] Wieland, M., Brenner R.P. and Sommer, P., (2003), "Earthquake resiliency of large concrete dams: Damage, repair, and strengthening concepts", Proceedings of the $21 \mathrm{st}$ International Congress on Large Dams, ICOLD, Montreal, Canada.

[17] Zhang, C., Pan, J. and Wang, J., (2009), "Influence of Seismic Input Mechanisms and Radiation Damping on Arch Dam Response", Soil Dynamics and Earthquake Engineering, 29, pp.1282-1293. 